\title{
David J. Slutsky, A. Lee Osterman (eds): Fractures and injuries of the distal radius and carpus. The cutting edges
}

\author{
Saunders Elsevier, Philadelphia, 2009563 pp, num figs, Hardcover XXX US \$, \\ ISBN 978-1416040835
}

Pierre Kehr

Received: 15 August 2009 / Accepted: 18 August 2009 / Published online: 28 August 2009

(C) Springer-Verlag 2009

Here is a very complete book describing the state-of-art treatments not only of the fractures and traumatisms of the lower end of the two bones of the forearm, but also of traumatic ligamentous lesions of the carpus and of fractures of the scaphoid as well as ulno-radial complex.

The traditional treatments as well as the more recent techniques like the arthroscopy in the articular fractures and fixings by locked plate of the fractures of the radius are described.

The many chapters make it possible to have an idea of the various available treatments, but the absence of the synopsis which gives a clear idea of control to be adopted with a decision tree, at the end of each chapter is regrettable.

Nevertheless this is a very interesting book, built well with a rich iconography and interesting remarks concerning the complications, the contraindications and the traps to be avoided.

A good book of reference with regard to the traumatology of the lower end of the forearm and the carpus.

No funds were received in support of this study.

Alain Graftiaux

P. Kehr (殴

ArgoSpine, Strasbourg, France

e-mail: kehrpier@aol.com 